\title{
Contrast thresholds for identification of numeric characters in direct and eccentric view
}

\author{
HANS STRASBURGER \\ University of Munich, Munich, Germany \\ LEWIS O. HARVEY, JR. \\ University of Colorado, Boulder, Colorado \\ and \\ INGO RENTSCHLER \\ University of Munich, Munich, Germany
}

\begin{abstract}
Aubert and Foerster (1857) are frequently cited for having shown that the lower visual acuity of peripheral vision can be compensated for by increasing stimulus size. This result is seemingly consistent with the concept of cortical magnification, and it has been confirmed by many subsequent authors. Yet it is rarely noted that Aubert and Foerster also observed a loss of the "quality of form." We have studied the recognition of numeric characters in foveal and eccentric vision by determining the contrast required for $67 \%$ correct identification. At each eccentricity, the lowest contrast threshold is achieved with a specific stimulus size. But the contrast thresh olds for these optimal stimuli are not independent of retinal eccentricity as cortical magnification scaling would predict. With high-contrast targets, however, threshold target sizes were consistent with cortical magnification out to $6^{\circ}$ eccentricity. Beyond $6^{\circ}$, threshold target sizes were larger than cortical magnification predicted. We also investigated recognition performance in the presence of neighboring characters (crowding phenomenon). Target character size, distance of flanking characters, and precision of focusing of attention all affect recognition. The influence of these parameters is different in the fovea and in the periphery. Our findings confirm Aubert and Foerster's original observation of a qualitative difference between foveal and peripheral vision.
\end{abstract}

It has been known for more than 130 years that under photopic conditions visual performance is lower in peripheral vision than it is in foveal vision (Aubert \& Foerster, 1857; Wertheim, 1894). There are two ways of specifying visual performance: to specify the stimulus properties necessary to achieve a certain level of performance, and to specify the level of performance reached with fixed stimuli. Specifications of the first type include the stimulus luminance, contrast, spatial frequency, or size. Specifications of the second type include percent correct, $d^{\prime}$, and reaction time. Threshold measurements are of the first type, since they are expressed in terms of some stimulus property required for constant performance.

Alphanumeric characters have been used in many studies of visual resolution, and visual acuity may be defined in terms of the smallest character that can be identified with a specified level of accuracy. But to use the size of a

Preparation of this article was supported by the Fraunhofer-Gesellschaft, Grant InSan I-1088-V-6389 to Ingo Rentschler, and by the Deutsche Forschungsgemeinschaft, Grant PO 121/13, Project 5, to Ingo Rentschler. We gratefully acknowledge Walter Encke for coauthoring the program for experimental control, and his and Bernhard Treutwein's constant helpfulness in all phases of the study. Requests for reprints should be sent to Hans Strasburger, Institute of Medical Psychology, Goethestr. 31, D-8000 München 2, Germany (E-mail: strasburger@psychologie.medizin.unimuenchen.dbp.de). character to specify visual performance produces an interaction with the spatial inhomogeneity of the visual system. The mapping from the visual field onto the visual cortex is nonlinear (Cowey \& Rolls, 1974; Daniel \& Whitteridge, 1961; Schwartz, 1980; Van Essen, Newsome, \& Maunsell, 1984). Thus, changing the size of a stimulus changes the amount of cortical tissue stimulated by the stimulus, with the degree of change depending on the location of the target in the visual field. It is desirable, therefore, to characterize the visual processing properties of a particular retinal locus by holding the size of the visual stimulus constant and varying the stimulus contrast.

In the 130 years since Aubert and Foerster (1857) first systematically studied the change in visual ability at different points within the visual field, researchers have isolated at least two types of functions that describe the degradation of performance that occurs as retinal eccentricity increases. The first type, applicable to tasks that require the detection of luminance gradients, is shown, among others, by two-point separation threshold (Aubert \& Foerster 1857), grating acuity (Wertheim 1894), Snellen acuity (Ludvigh, 1941; Virsu, Näsänen, \& Osmoviita, 1987), Panum's fusion area (Ogle, 1950) (for a review of the early literature see Weymouth, 1958), and grating contrast sensitivity (Hilz \& Cavonius, 1974; Kelly, 1984; Koenderink, Bouman, Bueno de Mesquita, \& Slappendel, 1978, Pt. III; 
Virsu \& Rovamo, 1979; Virsu, Rovamo, Laurinen, \& Näsänen, 1982). These acuity functions show a pattern of degradation that parallels the reduction of retinal ganglion cell density in the retina (cf. Perry \& Cowey, 1988 , and Wässle, Grünert, Röhrenbeck, \& Boycott, 1989, for ganglion cell distribution). The second group of visual functions are not directly related to ganglion cell density and often fall off faster toward the periphery. This group includes several hyperacuity measures, such as vernier acuity (Bourdon, 1902; Hering, 1899; Levi, Klein, \& Aitsebaomo, 1985; Weymouth, 1958), single-line vernier (Westheimer, 1982) and two-dot vernier (Westheimer, 1982; but see Virsu et al., 1987, p. 1574), as well as contrast of small uniform fields (Harvey \& Pöppel, 1972, or Pöppel \& Harvey, 1973), apparent movement of counterphased gratings (Hilz, Rentschler, \& Brettel, 1981), stereoacuity (Fendick \& Westheimer, 1983), grating orientation (Spinelli, Bazzeo, \& Vicario, 1984; but see Virsu et al. 1987, p. 1574), numerosity judgment (Parth \& Rentschler, 1984), bisection of a straight line (Levi \& Klein, 1986; Virsu et al. 1987), Landolt acuity (Virsu et al., 1987), pattern symmetry (Rentschler \& Treutwein, 1985; Saarinen, 1987), spatial phase quantization sensitivity (Harvey, Rentschler, \& Weiss, 1985), masking by spatially correlated noise (Hübner, Rentschler, \& Encke, 1985), and localization (Burbeck \& Yap, 1990). (For partial reviews see Pointer, 1986 and Virsu et al., 1987.)

Since the beginning of this century, it has been known that the readability of character groups cannot easily be deduced from individual character recognition (Wagner, 1918; for an overview of the older literature see Townsend, Taylor, \& Brown, 1971). Specifically, the recognition of a target character is more difficult in the presence of neighboring characters. This effect, first described by Ehlers in 1936 (Ehlers, 1936, 1953) and Woodrow (1938, p. 93), was later called the "crowding effect" by Stuart and Burian (1962). A variety of other names have been used in the literature to describe the crowding effect, including: "contour interaction" (Flom, Heath, \& Takahaski, 1963), "interaction effects" (Bouma, 1970), "lateral inhibition" (Townsend et al., 1971), "lateral masking"' (Geiger \& Lettvin, 1986; Monti, 1973; Taylor \& Brown, 1972; Wolford \& Chambers, 1983), and "'masking"' (Anstis, 1974). We will use the term crowding effect in this paper. The crowding effect is especially strong in amblyopic vision as well as in normal peripheral vision. It is also found, to a lesser extent, in foveal vision (Flom, Weymouth, \& Kahneman, 1963; for a review of the crowding effect see Wolford \& Chambers, 1983, and Atkinson, Pimm-Smith, Evans, Harding, \& Braddick, 1986). It is thus easier to identify characters when they are presented alone than when other characters are nearby. Since much of our visual information is picked up first in the peripheral visual field, and since amblyopic vision in the fovea seems to resemble normal peripheral vision to some extent, we studied the crowding effect with targets of different sizes in both foveal and peripheral vision. We used digits as targets, because digits are widely used in various information displays in the real world.

The determination of contrast thresholds has become a standard psychophysical method when the stimuli are gratings (see Braddick, Campbell, \& Atkinson, 1978) or twodimensional patterns processed through image-processing techniques (for a review see Caelli, 1986). For the assessment of recognition of simple optotype-like patterns, however, the contrast threshold has rarely been used. The exceptions may be found in a series of studies done with a paradigm introduced by Aulhorn (1960), in which the contrast threshold for discriminating a circle from a square target is determined within the Tübinger perimeter (Aulhorn, 1960, 1964; Aulhorn \& Harms, 1972; Johnson, Keltner, \& Balestrery, 1978; Lie, 1980). Further exceptions include an extensive investigation by Fleck (1987), in which the contrast threshold for the identification of characters as displayed on standard computer terminals was measured, and the recent introduction of Regan's, as well as Pelli and Robson's, low-contrast letter charts (Pelli, Robson, \& Wilkins, 1988; Regan, 1988a, 1988b). This neglect of contrast as a criterion variable is curious. Even Johnson et al. (1978) did not explicitly report contrast thresholds, but rather luminance threshold on a constant background. Apart from the observation that the grating and optotype lines of investigation stem from different traditions, we have no explanation for this neglect. The widespread use of the contrast-sensitivity function as a tool to understand the mechanisms of visual processing makes it desirable to relate the older types of measurements with those based on contrast sensitivity. We wish to bring together these two types of experiments. We have measured the target contrast required for threshold identification performance, using a wide range of target sizes in both foveal and peripheral vision. In this way, we hope better to understand the relationships among target size, the crowding effect, and retinal locus.

\section{METHOD}

\section{Stimuli}

The 10 digits $0-9$, in various retinal sizes, served as the stimuli in these experiments. The stimuli were displayed on a black and white CRT monitor (Barco TVM 3/37), using a Videograph digital image processing system. A DEC LSI-11/23 computer controlled both the image generation and the experimental procedure. Since the image processor's 8-bit gray scale resolution, even in conjunction with its gray value look-up table, is not sufficient for obtaining reliable contrast thresholds, contrast was manipulated with a digitally controlled video signal attenuator. With this attenuator, the video signal's contrast could be varied in steps of $1 / 80 \mathrm{log}$ units over a range of $2 \mathrm{log}$ units. Stimuli were displayed as light patterns on a uniform gray background. The background luminance of $62 \mathrm{~cd} / \mathrm{m}^{2}$ remained unchanged during the experiment, to provide for constant adaptation conditions. The stimulus luminance could be varied between that of the background and a maximum of $166 \mathrm{~cd} / \mathrm{m}^{2}$. A maximum of $46 \%$ contrast was possible under these conditions. Note that all contrast values reported in this paper are Michelson contrasts, as is common in the specification of the contrast of sine-wave grating patterns: 


$$
C=\frac{L_{\max }-L_{\min }}{L_{\max }+L_{\min }} .
$$

For low-contrast light patterns on a darker background, Michelson contrast is about half the contrast value obtained with the contrast definition commonly used for small targets against a larger background: $C=\left(L_{\max }-L_{\text {back }}\right) / L_{\text {back }}$. Note the nonlinear relationship between these two definitions.

The relationship between the display's luminance and the 8-bit gray value was measured with a Spectra Physics Litemate photometer. This relationship was used by the control program to compensate for the display nonlinearities. The stimulus digits were generated within a matrix 35 pixels high and 25 pixels wide. On the display screen, this matrix was $11.3 \mathrm{~mm}$ high and $8.1 \mathrm{~mm}$ wide, and the digits were drawn with lines $1.6 \mathrm{~mm}$ wide. The set of digit characters is shown in Figure 1. Since crowding effects are found with both short and long exposures (Townsend, Taylor, \& Brown, 1971), we used a fixed target exposure of $100 \mathrm{msec}$ in all our experiments.

\section{Position in the Visual Field}

The stimuli were viewed binocularly and were presented foveally or in the left visual field at eccentricities of $2^{\circ}, 4^{\circ}, 6^{\circ}, 8^{\circ}, 10^{\circ}$, $12^{\circ}, 14^{\circ}$, and $16^{\circ}$. Eccentricity is measured from the fovea to the middle of the stimulus target. We had chosen binocular viewing, because most real-world tasks are binocular. At the three largest eccentricities, the blind spot may have influenced the results; Subject M.B.'s blind spot ranged from $12^{\circ}$ to $15.5^{\circ}$. But because we did not find any discontinuities there, we are confident that our conclusions were not compromised by the use of binocular viewing. In the experiments on the crowding effect, the target digit was presented with two other digits, one to the left and one to the right on the horizontal meridian. The separation between the target and the flanking characters can be expressed both as the angular distance between the character midpoints and as the number of lettersize units between the digit centers, using the vertical size of the digits as a reference size because vertical size is the same for all 10 of the digits. With the pixel matrix used in this experiment, a distance of 1 letter-size unit corresponds to a free space between characters of $2 / 7$ of the distance between their centers.

\section{Subjects}

Three paid subjects ( 2 females and 1 male, with ages of 20-30 years) and the first and second authors (male, with the ages 38 and 41 years) served as subjects. All subjects had normal or fully corrected vision.

\section{Psychophysical Procedure}

The digits were presented in random order, one at a time at a fixed eccentricity in the visual field, and the subject's task was to identify the target digit. The target contrast for each trial was determined by a computer-controlled, maximum-likelihood adaptive
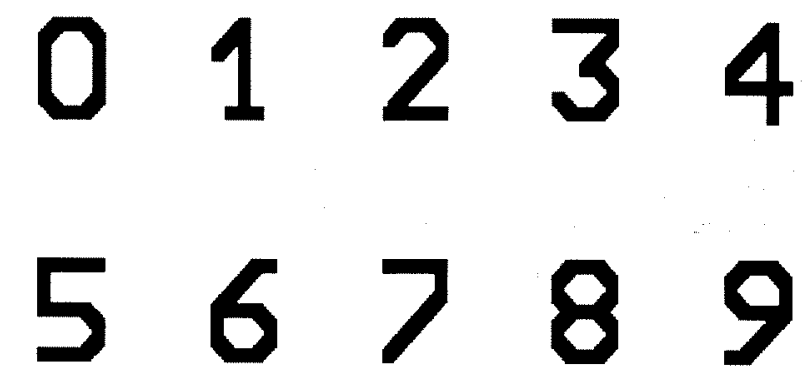

Figure 1. The stimulus set of digits used in the experiments. procedure. In this method, which is variably called Best-PEST, QUEST, or ML-TEST (Harvey, 1986), before each stimulus presentation, the likelihood distribution of possible thresholds is calculated by using the Weibull psychometric function with a slope of 3.5 , on the basis of the subject's set of responses up to this point. The contrast value with the maximum likelihood of being the threshold contrast is then chosen for the presentation. This method is an optimum strategy for a fast threshold determination. In effect, the algorithm raises the target contrast after a wrong response and lowers it after a right response. We terminated the procedure when the contrast threshold had been determined with a $95 \%$ confidence interval of $0.15 \log$ units. About 30-40 trials were usually required to attain this accuracy $\left(36 \pm 5\right.$ foveally and $37 \pm 9$ at $16^{\circ}$ for Subject M.B.). Since there were 10 possible digits, the probability of correctly identifying a digit by chance alone was $10 \%$ and threshold contrast was the contrast giving a probability of correct identification of $67 \%$ (the point of inflection on a Weibull function with a base of 10\%). The principles of this method are described by Hall (1968), Pentland (1980), Watson and Pelli (1983), and Harvey (1986). The program for experimental control used a subroutine package, written by the second author (Harvey, 1986), that implemented a general-purpose maximum-likelihood procedure. The package is now available in the languages FORTRAN, C, and Modula-2 from the authors.

We varied target size by using different viewing distances; the minimum distance was $46 \mathrm{~cm}$ (resulting in $1.4^{\circ}$ size). At each retinal locus, the testing sequence proceeded from the largest target size to the smallest and then from the smallest size to the largest. The log contrast threshold data presented in the figures are the means of these descending and ascending series of trials.

\section{PRELIMINARY EXPERIMENTS}

Under ideal conditions, the contrast threshold would only depend on the retinal stimulus size and not on the size on the display screen. In our equipment setup, however, thresholds increased with small display sizes. This threshold increase is not due to pixel blurring like that described by Morgan and Watt (1982), for example; it was caused by the limited bandwidth of the video signal attenuator used to control contrast, which reduced the sharpness of stimulus edges. In a preliminary experiment, we tested how the contrast threshold was influenced by the actual size of the stimulus on the screen while holding retinal image size constant.

Contrast thresholds were measured for various target sizes with different viewing distances, to keep the angular subtense of the target constant at $0.5^{\circ}$. The results are shown in Figure 2A. For letter heights above $10 \mathrm{~mm}$, performance is independent of size, but below $10 \mathrm{~mm}$, performance is severely degraded. For example, six times more contrast is required to recognize $3-\mathrm{mm}$ targets compared with $10-\mathrm{mm}$ ones. Consequently, in our subsequent measurements, we have only used sizes of $11.3 \mathrm{~mm}$. The effect of the bandwidth reduction is not easily seen by an observer looking at high-contrast targets on the screen. We have found that the determination of the contrast threshold is a much more sensitive and reliable way of quantifying image quality.

In the main experiments, the stimuli were lighter than the background. We were concerned that the results might not be comparable to those obtained with stimuli darker 
(A)

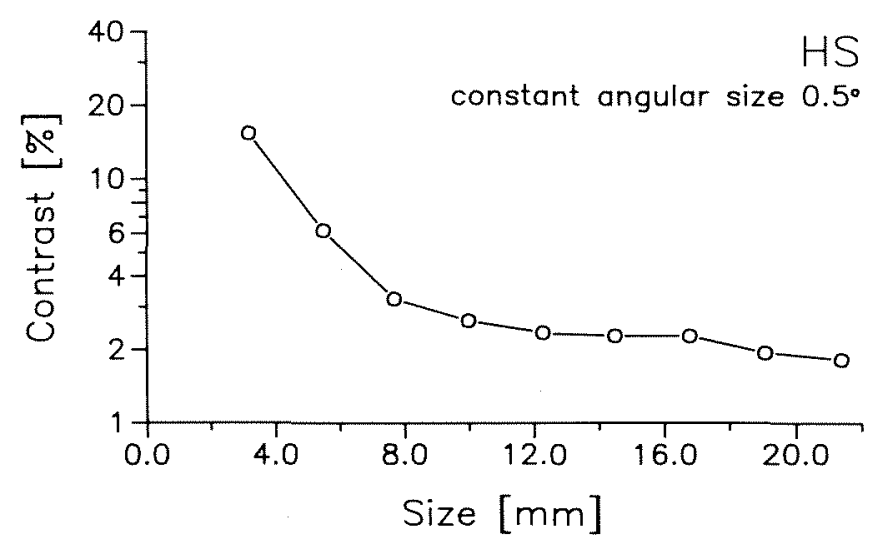

(B)

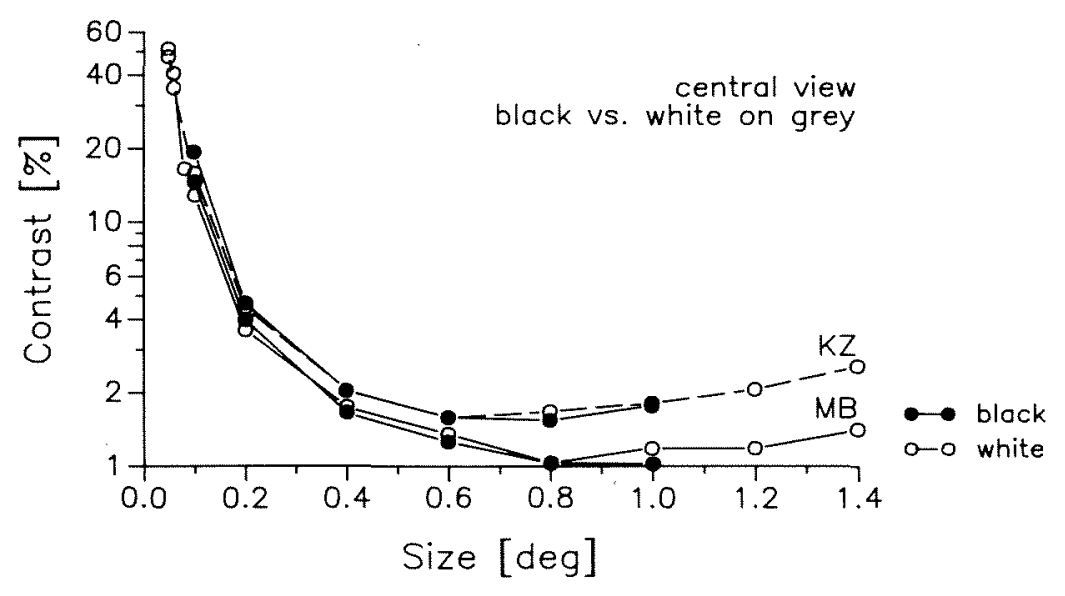

(C)

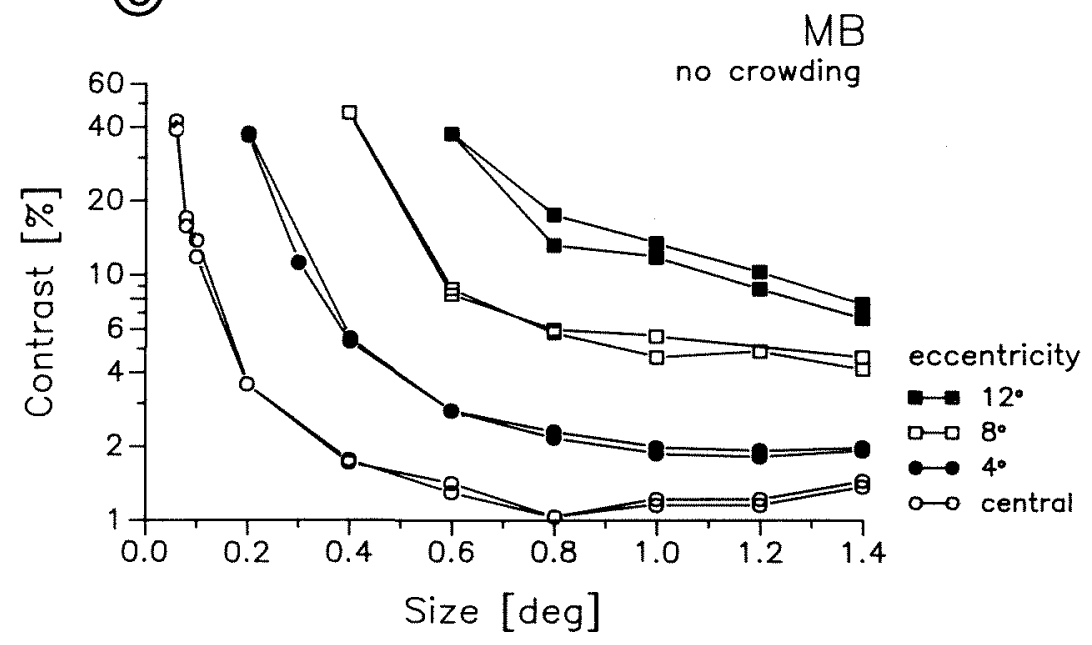

Figure 2(A). Mean log threshold contrast as a function of target size on the display screen for constant angular size of $0.5^{\circ}$. (B) Mean log contrast threshold for light and for dark letters for sizes ranging from $0.1^{\circ}$ to $1.0^{\circ}$ viewed at the fovea. (C) Mean $\log$ contrast threshold for letters of sizes ranging from $0.06^{\circ}$ to $1.0^{\circ}$ in a descending and an ascending series of sizes at retinal eccentricities of $0^{\circ}, 4^{\circ}, 8^{\circ}$, and $12^{\circ}$. 
than the background, as is usually found with printed material. The contrast thresholds of dark letters of different sizes were measured at various retinal eccentricities, and the results were compared with thresholds for light letters measured under the same conditions. A comparison of the contrast thresholds for light and dark letters is made in Figure 2B. As can be seen in the figure, the contrast thresholds for the two types of stimuli are virtually identical. We are therefore confident that our results, obtained with light letters, can be applied to dark letters as well.

In the main experiments, the subjects were tested at a fixed retinal eccentricity, with the largest digit size first. Thresholds were then measured with smaller and smaller sizes until the contrast limit of the display setup was reached. If at the highest obtainable contrast the criterion performance of $67 \%$ is not reached, due to its interpolation algorithm the ML-test procedure returns threshold contrast results that are slightly above the physically possible value. The series was then repeated, starting with the smallest digit size and progressing to the largest. The results of one of these series are shown in Figure 2C. One can see in the figure that the contrast thresholds are not influenced by the use of either a descending or an ascending size series. Also evident in the figure is the reliability of the measurements. Since it is unusual in the literature to find reports of recognition contrast sensitivity for alphanumeric characters, we wish to emphasize that these types
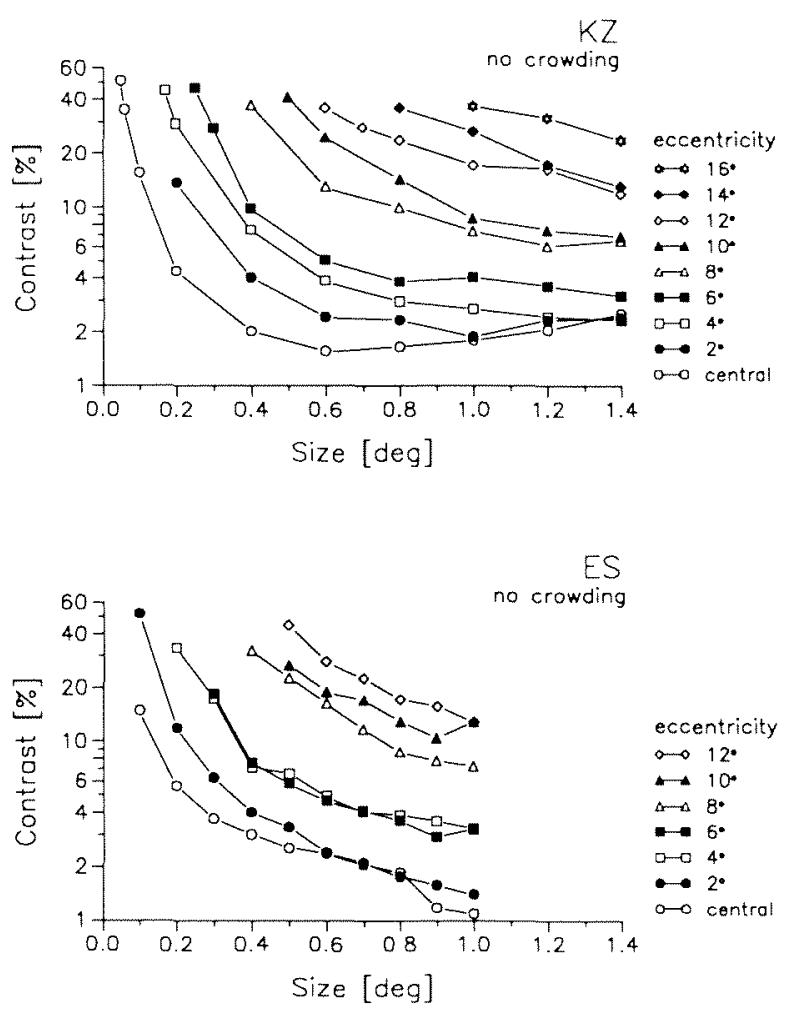

of threshold measurements with complex characters are highly reliable and should be of use with a patient population as well as with people with normal vision.

\section{MAIN EXPERIMENTS}

\section{Experiment 1: Contrast Sensitivity and Character Size}

In the next experiment, the contrast thresholds for recognition of the 10 digits were measured as a function of the target angular sizes ranging from $0.06^{\circ}$ to $1.4^{\circ}$. The digits were presented in the fovea and in the left visual field at retinal eccentricities of $2^{\circ}, 4^{\circ}, 6^{\circ}, 8^{\circ}, 10^{\circ}, 12^{\circ}$, $14^{\circ}$, and $16^{\circ}$. Subjects M.B. and K.Z. served in all the experimental conditions; Subjects E.S. and H.S. served only in a subset of the conditions. The data for these 4 subjects are shown in Figure 3.

With foveal viewing, the contrast threshold is largely independent of target size above $0.6^{\circ}$, although there is a small increase in threshold for the largest sizes. For sizes below $0.6^{\circ}$, contrast threshold dramatically increases, and at the lowest sizes $\left(0.06^{\circ}\right)$, the maximum contrast attainable with our setup, $46 \%$, was insufficient for target recognition.

In peripheral vision, contrast thresholds for identification increase. The function relating contrast threshold to target size has a shape similar to that of the foveal curve, but it is shifted toward larger target sizes. The maximum
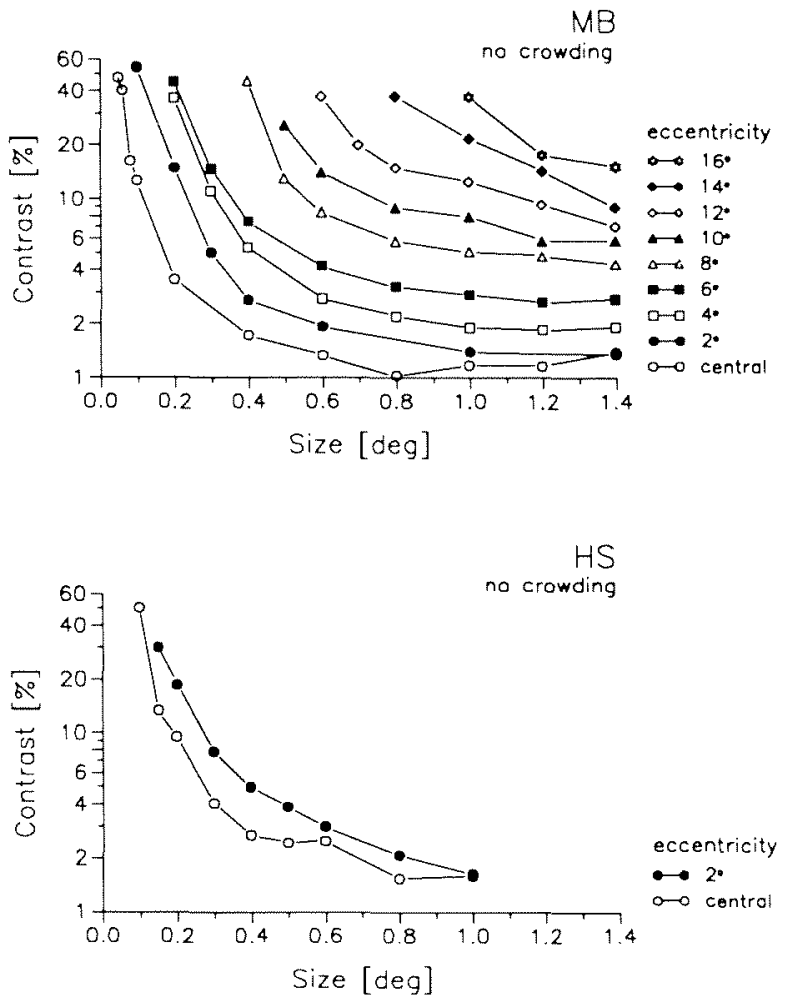

Figure 3. Mean log contrast threshold as a function of angular target size, for central and eccentric view for 4 subjects. 
sensitivity is also systematically reduced, the farther into the peripheral visual field the targets were presented. The effect, therefore, of eccentric target presentation is to produce a shift to the right and upwards of the foveal threshold curve.

For Subject K.Z., for example, the lowest contrast threshold for foveal viewing was $1.6 \%$; at $2.0^{\circ}$ eccentricity, it was $1.9 \%$; and at $10^{\circ}$, it was $6.9 \%$. At larger eccentricities, a minimum contrast threshold was not found within the range of target sizes used: Targets larger than $1.4^{\circ}$ apparently would have been necessary to find this minimum.

Unlike the familiar way of plotting a contrast-sensitivity function, the size variable is scaled linearly in these figures. The use of a logarithmic (spatial frequency) axis would result in the curves' appearing more curved. We further want to point out that if we extrapolate these curves to a fixed high contrast, the limit corresponds to a conventional acuity test. From our data, the limit for $100 \%$ contrast can be estimated to be $0.04^{\circ}\left(2.4^{\prime}\right)$ for foveal view, which is in the range of $0.04^{\circ}-0.08^{\circ}$ of conventional acuity measurements expressed in height of the optotypes for acuities of 1.0-2.0.

\section{Experiment 2: Lateral Masking or Crowding Effect}

In everyday situations, the appearance of individual characters is the exception rather than the rule; characters usually appear grouped into words or numbers. In
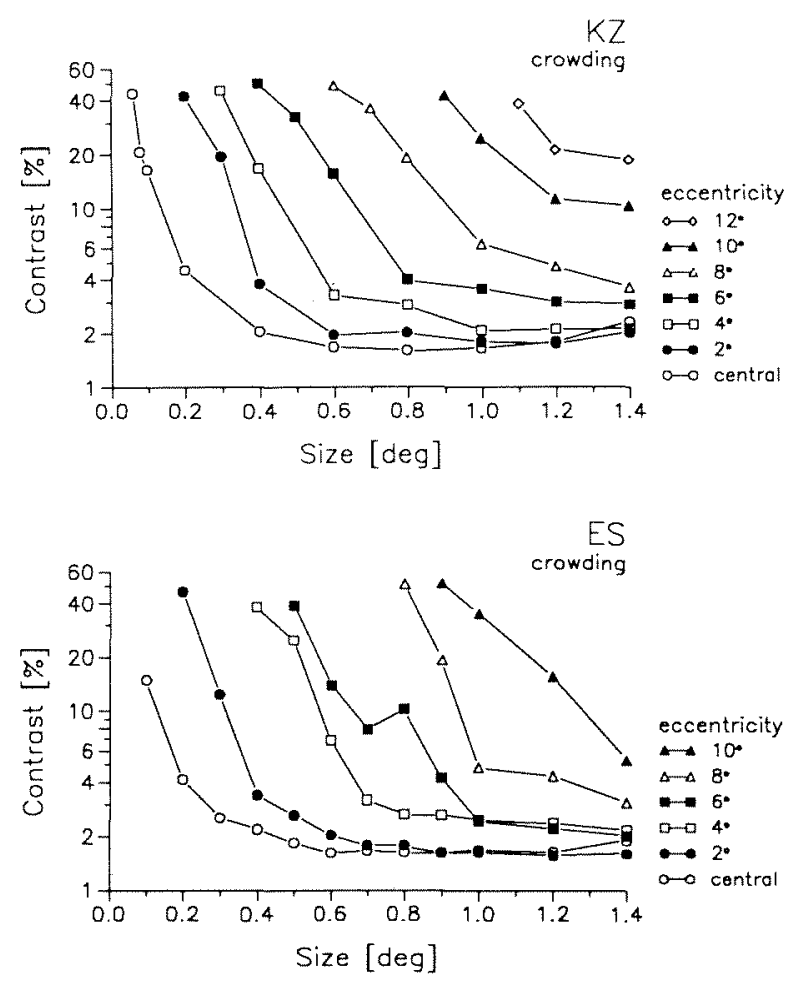

the next experiment, we investigated the influence of the crowding effect on digit recognition. We presented groups of three digits, and the subjects were asked to identify the middle one. The center-to-center distance from the flanking digits to the target digit was set at two letter-size units, which creates one blank space between the digits. As a consequence, the larger target sizes had larger distances to their flanking digits. The results from 4 subjects are presented in Figure 4. In order to make the effect of crowding more apparent, the data for 2 of these subjects are replotted separately for each of the seven eccentricities in Figure 5, together with their data for recognition of single digits taken from Figure 3 for each of the seven eccentricities. The crowding effect appears as a difference between these two curves. One sees in botr. Figures 4 and 5 that the crowding effect increases as retinal eccentricity increases. The effect is small, or possibly absent, in the fovea, yet already at $2^{\circ}$ from the fover the crowding effect is quite pronounced. It can also be seen that the crowding effect occurs only for letter: smaller than a critical size, where the curves in Figure : begin to diverge. At retinal eccentricities of $10^{\circ}$ and $12^{\circ}$ the range of digit sizes used is insufficient for such a claim The critical sizes taken from Figure 5 are reported in Ta. ble 1 . The other 2 subjects show similar results.

\section{Experiment 3: Effect of Crowding Distance}

There are two possible reasons why no crowding ef fect was found above the critical target size. The first i:
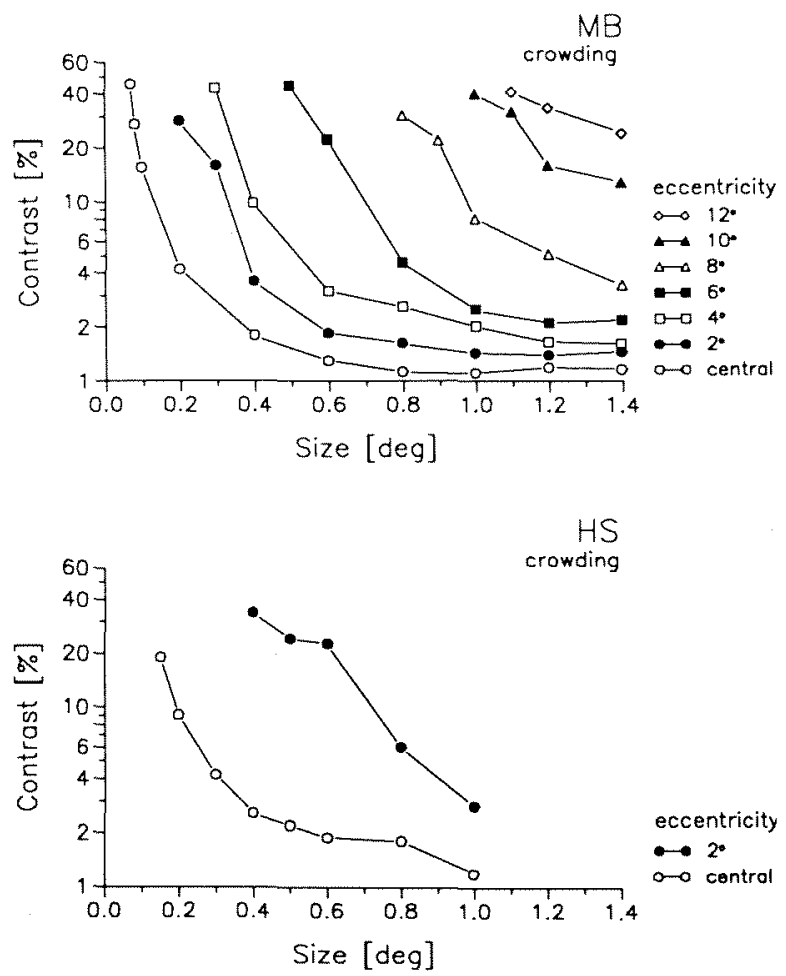

Figure 4. Mean log contrast threshold under crowding conditions. The target is flanked on the left and right by one additional digi at a center-to-center separation of 2 letter-size units. 

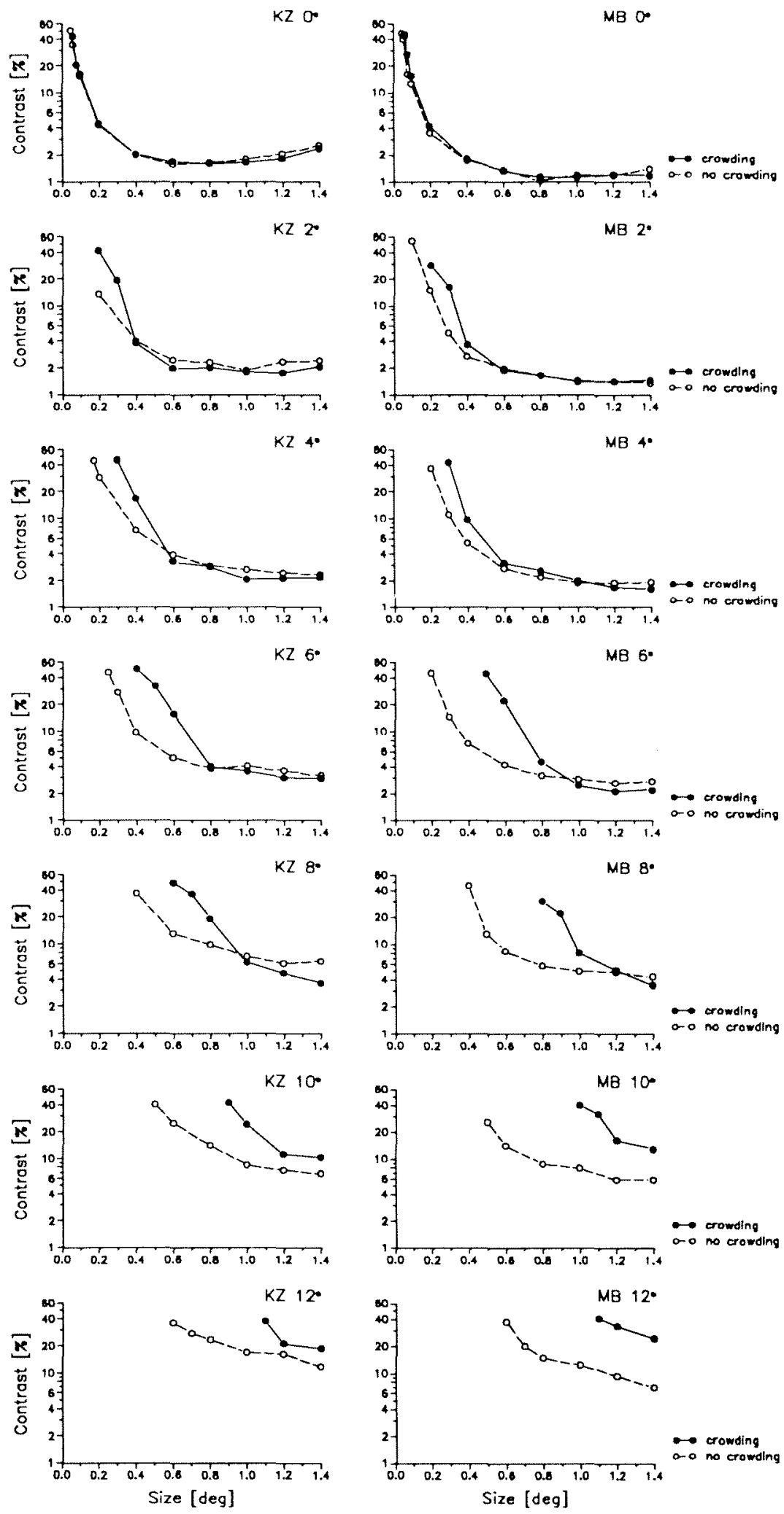

Figure 5. Mean log contrast thresholds under crowding conditions (closed circles, from Figure 4) compared with thresholds under no-crowding conditions (open circles, from Figure 3). 
Table 1

Critical Target Sizes From Figure 5

\begin{tabular}{ccc}
\hline & \multicolumn{2}{c}{ Critical Size } \\
\cline { 2 - 3 } Eccentricity & Subject K.Z. & Subject M.B. \\
\hline 0 & 0.4 & 0.6 \\
2 & 0.6 & 1.0 \\
4 & 0.8 & 1.0 \\
6 & 1.0 & 1.2 \\
8 & $>1.4$ & $>1.4$ \\
10 & $1.2-1.4$ & $>1.4$ \\
12 &
\end{tabular}

Note-All values are given in degrees of visual angle.

that the targets themselves are larger; the second is that the spacing between the targets is larger. To clarify which of these two factors is responsible, in the next experiment, the distance between the flanking and the target characters was varied in small steps while the letter size was held constant at seven different values ranging from $0.06^{\circ}$ to $1.0^{\circ}$. These measurements were made for foveal vision and for $4^{\circ}$ retinal eccentricity. Log threshold contrast is plotted in Figure 6 as a function of the center-to-center crowding distance in degrees of visual angle for the different digit sizes and for the two retinal loci. In this figure, the digit separations corresponding to two letter-size units, as was used in the previous experiment, are marked by a circle. Note that the smallest possible crowding distance depends on the letter size, since if the center-to-center spacing is less than 0.8 letter-size units, the digits wil] begin to overlap.

As is apparent from Figure 6A, the contrast threshold for foveal viewing is independent of character separation: even for the separation values that are lower than those used in the previous figure, a crowding effect is not present. For eccentric viewing (Figure 6B), a large crowding effect is apparent below about $1.2^{\circ}$ charactel separation, which vanishes at higher separation values. From the position of the circled data points, it can be seer that the relative character separation (i.e., in multiples of character size) is of little information; it is the absolute separation angle that is relevant. From the figure we can also deduce an explanation for why no crowding effect is present for large character sizes: The characters are just too large to have a center-to-center spacing closel than $1.2^{\circ}$.

A further question is whether in eccentric viewing the character size, for values below $1.2^{\circ}$, has any influence on the crowding effect's extent. In answer to this ques. tion, Figure 7 shows the previous figure's data, with size as the independent variable. As is apparent from the figure, except in one case (Subject K.Z. at $0.4^{\circ}$ distance). contrast threshold-at fixed character distance-increases as character size decreases. The effect is most pronouncec at sizes below about $0.6^{\circ}$. Consequently, both character size and character distance determine the crowding effect's extent.
(A)

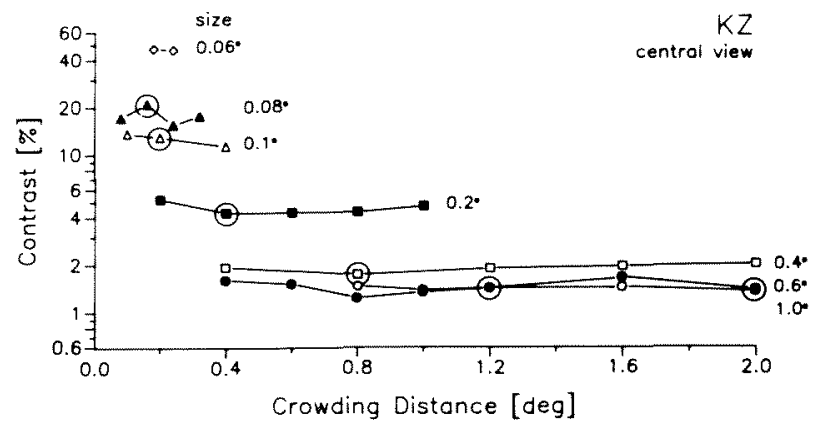

(B)

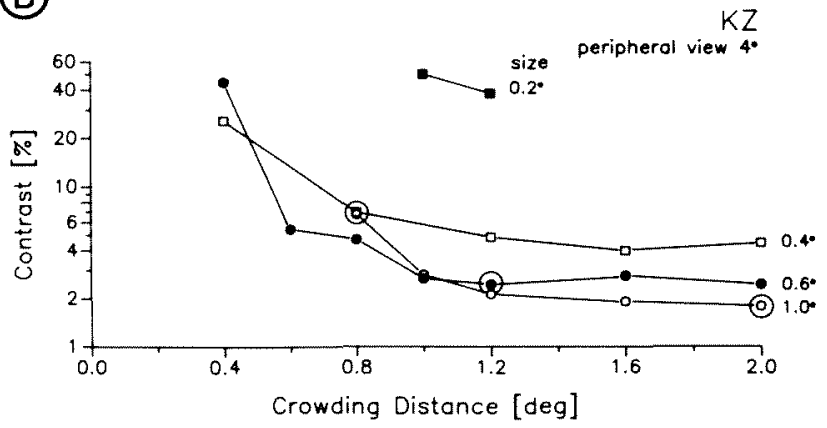

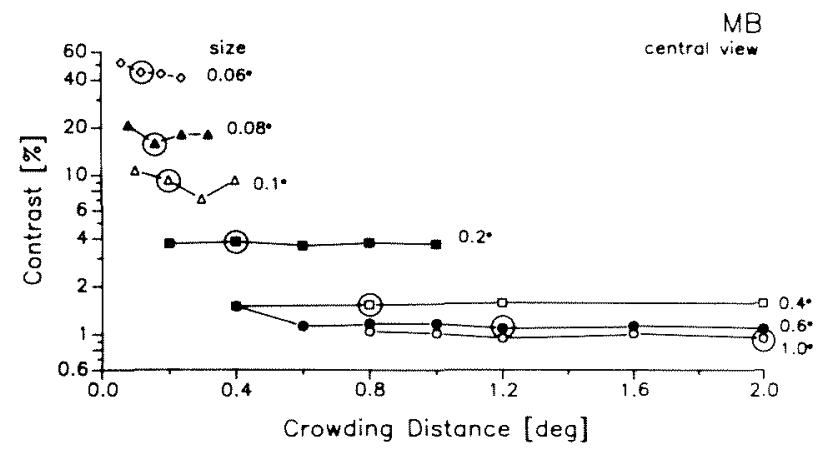

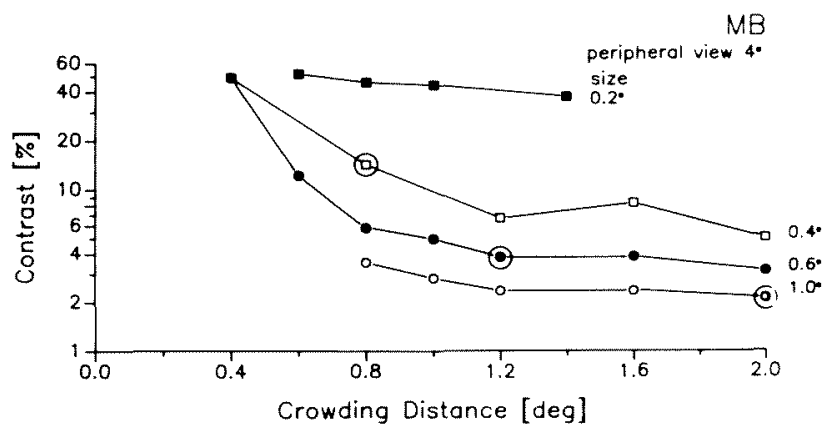

Figure 6. Mean log contrast threshold under crowding conditions as a function of distance of the flanking digits, for 2 subjects. (A) Foveal vision; target size $0.06^{\circ}$ to $1^{\circ}$. (B) $4^{\circ}$ left visual field; target size $0.2^{\circ}$ to $1^{\circ}$. 

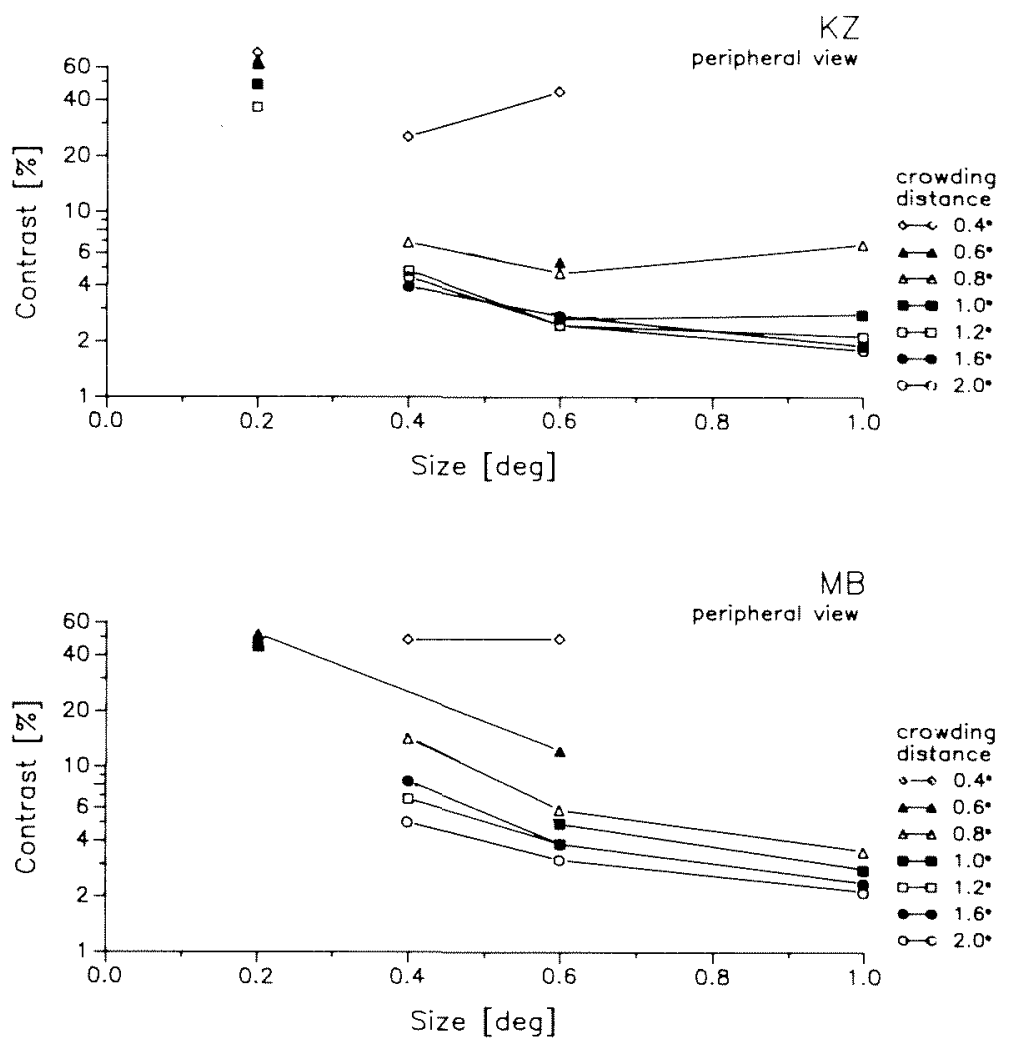

Figure 7. Mean log contrast thresholds from Figure 6, with target size as independent variable.

\section{Experiment 4: Effect of Number of \\ Flanking Characters}

Several experimenters have shown that the crowding effect becomes more severe the more flanking characters there are next to the target character. We therefore compared the crowding effect produced by one flanking digit on each side of the target (Experiment 3) with the effect produced when four flanking characters were used, two on either side of the target. The results are shown in Figure 8, where it can be seen that the crowding effect is more severe when four flanking characters are used than it is when two are used. This shows that crowding is not solely dependent on the closest contours. Although the additional characters are-according to the results of Experiment 3-too far away from the target to exert a crowding effect of their own, their presence in conjunction with that of the closer two characters does make a difference.

\section{DISCUSSION}

\section{Cortical Magnification}

Our results provide further evidence that the relative inferiority of peripheral vision cannot be fully compensated for by making alphanumeric targets larger. There are two aspects to this failure. The first concerns the acuity values at constant high-contrast thresholds. From the con- trast threshold data without crowding (Figure 3), we computed the letter sizes at which the contrast threshold reached a constant value. For contrasts below $40 \%$, the points can be read directly from the data of Figure 3 . The $100 \%$ points were obtained by using the foveal curve as a template that was fitted by eye to each of the peripheral curves. These sizes are equivalent to minimum angle of resolution measures used to specify visual acuity with letter optotypes. The target sizes as a function of retinal eccentricity are shown in Figure 9.

Aubert and Foerster's (1857) law had been related to the amount of brain tissue devoted to each particular part of the visual field. The linear extent in millimeters of visual cortex corresponding to each degree of the visual field is called the cortical magnification factor $M$. Anatomical studies show that the inverse of $M$ decreases approximately as a linear function of retinal eccentricity (Cowey \& Rolls 1974; Daniel \& Whitteridge, 1961; Van Essen et al., 1984). Scaling the size of peripherally presented targets by the inverse of $M$ has been proposed to compensate for the lower peripheral performance (Rovamo, Virsu, \& Näsänen, 1978; Virsu et al., 1987; cf. Koenderink et al., 1978, p. 854). A frequently employed relationship for $\boldsymbol{M}$-scaling is given by Equation 1 below (Rovamo \& Virsu, 1979, p. 498; Virsu \& Rovamo, 1979); predictions (Tolhurst \& Ling, 1988) based on more 

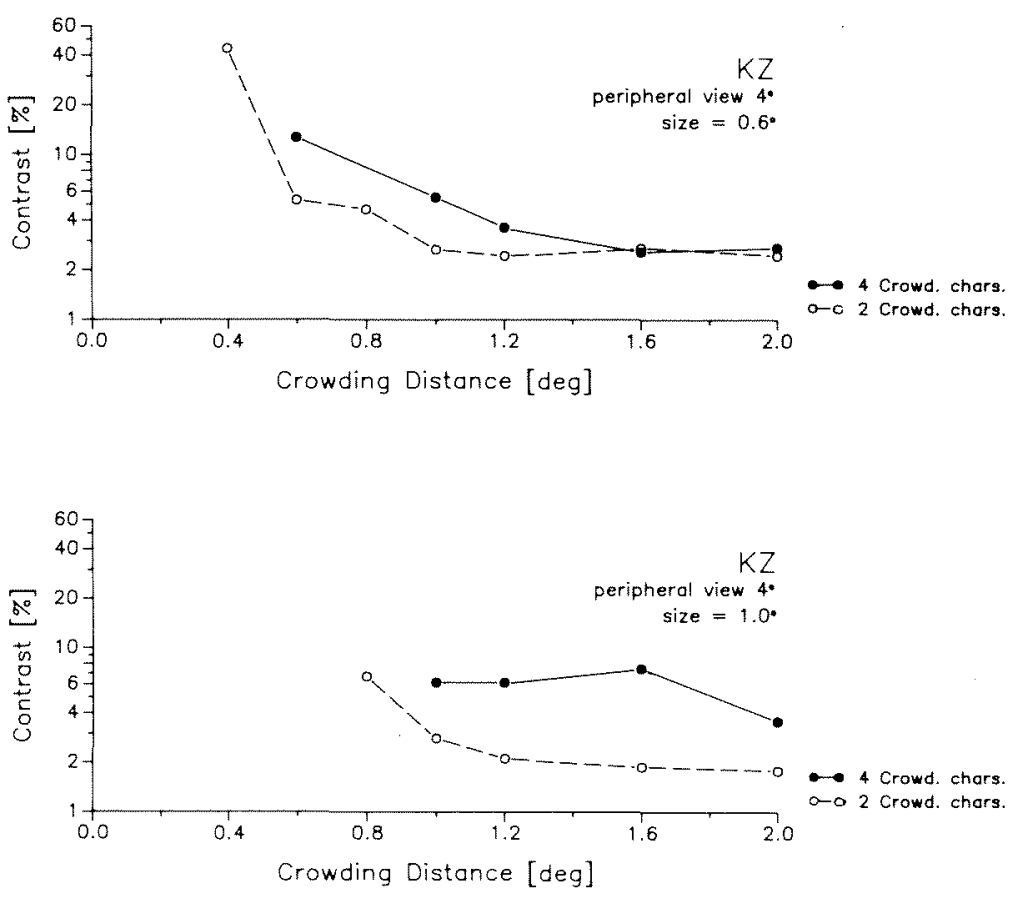

Figure 8. Log contrast thresholds for digit identification with two and four flanking characters, for two target sizes.

recent anatomical evidence (Van Essen et al., 1984) lead in our context to similar conclusions. Plotted in Figure 9 are the digit sizes predicted by the $M$-scaling of the foveal size according to the relationship

$$
S=S_{0}\left(1+0.33 E+0.00007 E^{3}\right),
$$

where $S$ is the predicted target size in degrees, $E$ is retinal eccentricity in degrees of visual angle, and $S_{0}$ is the threshold target size in the fovea. For the value of $S$, which determines both the slope and $y$-intercept of the scaling function, we used $0.07^{\circ}$, which was based on a leastsquares fit to the $2^{\circ}, 4^{\circ}$, and $6^{\circ}$ data points. One can see in Figure 9 that our data are in good agreement with the cortical magnification factor out to retinal eccentricities of $6^{\circ}$. Beyond $6^{\circ}$, however, our data indicate that for the fixed thresholds of $40 \%$ and $100 \%$, digits must be larger than predicted by cortical magnification.

The second failure of the cortical magnification concept is more severe. It can be seen in our finding that the minimum contrast thresholds reached by large targets in peripheral retinal loci are never as low as those reached by targets seen in foveal vision (Figure 3). It is clear from our data that to make the peripheral targets even larget than the largest that we have used would not lower the

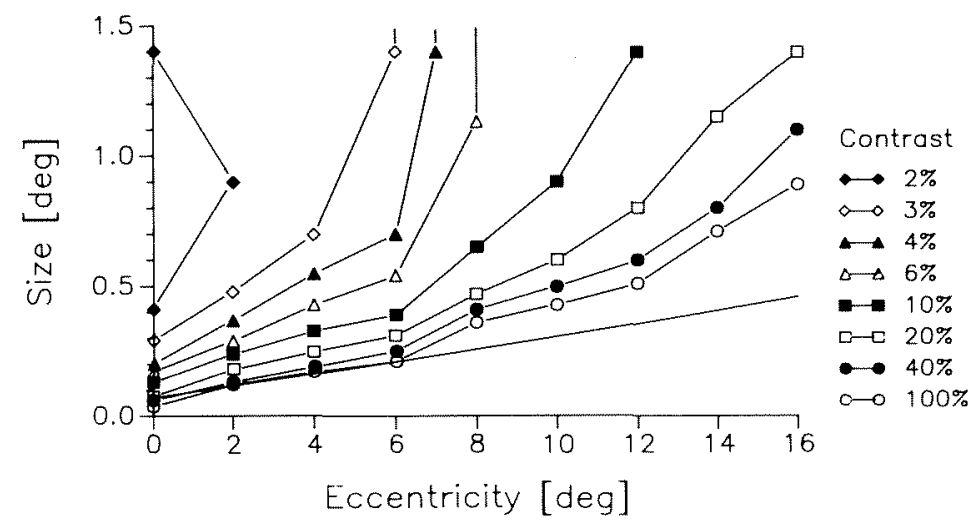

Figure 9. Minimum digit size for constant contrast thresholds as a function of retinal eccentricity from $0^{\circ}$ to $16^{\circ}$. The solid line shows the digit size predicted by the cortical magnification factor. 
contrast thresholds for most of the peripheral locations tested. Thus, independent of which specific function is used for scaling, no stimulus enlargement can compensate for the performance loss beyond $6^{\circ}$ eccentricity for contrasts below $4 \%$.

Although the $\boldsymbol{M}$-factor provides a sufficiently accurate description of acuity and contrast sensitivity for detection of simple stimuli (sine-wave gratings), our results show that the functional differences between fovea and periphery are not adequately captured when contrast sensitivity is measured with complex alphanumeric characters. The cortical magnification concept correctly describes functions of pattern energy detection, but not the more complex functions involved in pattern recognition.

\section{Crowding in the Fovea}

One sees in our data, at best, only a small crowding effect in the fovea, which at first may seem to be at variance with the results of previous studies. In fact, however, studies on the crowding effect in the fovea are scarce, and the results are often difficult to compare, because of methodological differences. The first quantitative data showing a foveal crowding effect are those of Thomas-Decortis (1959, p. 491), who reported a decrease by a factor of 1.3 in foveal acuity of normally sighted subjects. Character crowding distance was 1.2 letter-size units. Patterns were $E$ patterns with $2+2$ flanking patterns. Stuart and Burian (1962) also reported a foveal crowding effect, but they used very different stimuli and criteria. Averbach and Coriell $(1961$, p. 317) showed that a $1.5^{\circ}$ circle surrounding a $1^{\circ} \times 0.5^{\circ}$ letter has little effect when they are presented simultaneously but has a large effect when presented $100 \mathrm{msec}$ after the target stimulus. In a recent study, Atkinson, Anker, Evans, and McIntyre (1987) have reported that their adult control group also showed a decrease of acuity by a factor of 1.3 under crowding conditions as opposed to single letters; in the crowding condition, the target was surrounded by four letters, one to the left, the right, above, and below, at a distance of 1.5 letter-size units. The crowding distance in degrees was not given, but it can be inferred to have been around $0.1^{\circ}$ for a normally sighted subject. Contrast for the "Cambridge Crowding Cards" that were employed was probably at least $80 \%$. A similar result has been reported in Atkinson et al. (1986, p. 204).

In two papers (Flom, Heath, \& Takahashi, 1963; Flom, Weymouth, \& Kahneman, 1963), Flom and co-workers found that the crowding effect only occurred in the fovea when contours were less than $0.05^{\circ}$ apart. In our study, of the smallest clearly discernible characters, only those with a size of $0.08^{\circ}$ or $0.1^{\circ}$ at their minimum separation were close enough to satisfy this condition (Figure 6A). It may be that a crowding effect is just beginning to be apparent with these target sizes, but a strong crowding effect would only show up with still smaller target sizes. In order for these smaller targets to have been visible, a contrast higher than our maximum of $46 \%$ would have been necessary, as can also be seen in Figure 6A.

\section{Crowding in the Periphery}

Although the crowding effect is much more pronounced in the peripheral visual field than it is in the fovea, and although crowding effects in peripheral vision of amblyopes had already been described in 1959 by ThomasDecortis, quantitative reports for normal subjects appeared much later, the first one being a study by Bouma (1970). Bouma measured identification accuracy of tachistoscopically presented lowercase letters with a size of $0.22^{\circ}$ at eccentricities between $1^{\circ}$ and $8^{\circ}$, flanked by an additional letter on the left and the right with a character distance varying between $0.29^{\circ}$ and $4.6^{\circ}$ (1.3-20 letter-size units). He found a large crowding effect that increased as eccentricity increased. For sufficiently large character separations, the effect vanished, and the value at which this was the case could be roughly described as being half the angle of eccentricity. For $4^{\circ}$ eccentricity, for example, no loss of performance occurred above around $2^{\circ}$ letter separation (cf. Bouma's Figure 2). This value is somewhat larger than our result of $1.2^{\circ}$. The difference might owe to an overestimation in Bouma's value that was due to nonfeatural components of lateral masking, as Wolford and Chambers (1983, p. 137) have pointed out.

For foveal viewing, the crowding effect has been described as a form of "contour interaction" by Flom and co-workers (Flom, Heath, \& Takahashi, 1963; Flom, Weymouth, \& Kahneman, 1963). For peripheral viewing, our finding that the presence of four flanking characters leads to a larger crowding effect than does the presence of two shows that crowding is not solely dependent on the closest contours present.

Eriksen and Hoffmann (1972) showed that at $2^{\circ}$ eccentricity, crowding occurs for a spacing of $0.5^{\circ}$ but not $1.0^{\circ}$. Townsend et al. (1971), Taylor and Brown (1972), and Monti (1973) investigated properties of peripheral crowding for stimulus material containing many elements; their results thus cannot be easily compared to ours. Shaw's (1969) intriguing results on the role of a blank space in a string of 10 letters subtending $4^{\circ}$ seems to us also to involve the crowding effect. Fleck (1987) measured contrast thresholds for identifying single, visually degraded letters of the alphabet with and without flanking letters, presented at different retinal loci. His letters were $0.6^{\circ}$ high and $0.3^{\circ}$ wide. In agreement with our results, Fleck found that contrast thresholds for the letters rose at a higher rate for retinal loci greater than $6^{\circ}$. He also found a significant increase in contrast thresholds when flanking letters $2^{\circ}$ from the target were present.

\section{Causes of the Crowding Effect}

Two possible explanations for the crowding effect are considered here. The first is that contrast sensitivity in the target area is reduced by the presence of other edges or contours nearby. The second explanation is that it is difficult to move one's attention away from the fixation point to the eccentric visual field locus containing the target stimulus. The notion that the focusing of attention to eccentric locations rather than fixation plays an impor- 
tant role in peripheral vision was already proposed by Wagner in 1918. In this paper, Wagner discusses the role of the "distribution of attention" in the recognition of printed text.

Wolford and Chambers (1983) quantitatively separated the effects of attention and feature interaction on the recognition of closely spaced characters. At $5^{\circ}$ eccentricity, they presented targets spaced $0.3^{\circ}$ and $1^{\circ}$ apart, with additional vertically arranged characters serving as a cue for the focusing of peripheral attention. With this stimulus arrangement, they showed that feature interaction was more prominent at $0.3^{\circ}$ spacing, whereas the effect of cuing dominated at $1^{\circ}$ spacing. Duncan (1985) has put this work into a framework of search and attention based on Broadbent's (1958) two-stage filter theory. It should be noted that Shaw $(1969$, p. 261$)$ found that voluntary attention shifts did not seem to affect performance.

Wolford and Chambers (1983) separated attention and feature interaction relative to a given level of crowding effect (see their Figure 4) but did not quantify the absolute contribution of these factors. In the present experiment, there is a way of assessing the extent to which insufficient focusing of attention is responsible for the reduced sensitivity, since the flanking stimuli are from the same pool as were the targets. On some trials, the subject's response was incorrect in terms of the target digit but was correct in terms of one of the flanking targets. Let us assume that the "correct" identification of the flanking target was due to an inadvertent shift of attention. With the data of Experiment 3, we determined within the set of wrong responses the subset of those which corresponded to one of the flanking digits. The resulting identification performance for foveal viewing and $4^{\circ}$ eccentricity is shown in Table 2.

In the data of Experiment 3 (Figure 6), the total number of errors for Subjects K.Z. and M.B. was 400 for foveal vision and 498 for peripheral vision. On trials on which the subject incorrectly identifies the target, there is a $20 \%$ chance that the response identifies correctly one of the two flanking digits. In the data for foveal vision, $19 \%$ of these wrong answers corresponded to a flanking digit, which is not significantly different from the expected chance level of $20 \%$. At $4^{\circ}$ retinal eccentricity, however, $42 \%$ of the wrong answers corresponded to a flanking digit, a highly significant value. If we subtract the chance performance of $20 \%$, we can state that every fifth wrong response at $4^{\circ}$ in the periphery is caused by difficulties in focusing attention. The flanking letter farther from the fovea was identified as often as the flanking letter nearer to the fovea. Whether or not other causes besides the shift

Table 2

Percent of Flanking Digits Correctly Identified in Wrong Responses for Foveal and for $4^{\circ}$ Eccentric Vision

\begin{tabular}{lccrc}
\hline & Overall & \multicolumn{3}{c}{ Correspondence } \\
\cline { 3 - 5 } & Errors & Left & Right & Left + Right \\
\hline Foveal & 400 & $11 \%$ & $8 \%$ & $19 \%$ \\
$4^{\circ}$ peripheral & 498 & $21 \%$ & $21 \%$ & $42 \%$ \\
\hline
\end{tabular}

of attention problem contribute to a threshold elevation in peripheral vision remains to be investigated.

\section{Mechanisms Underlying Crowding}

What mechanisms underlie the crowding phenomenon? Flom, Weymouth, and Kahneman (1963, Figure 2), studying foveal contour interaction in normal and amblyopic eyes, found a striking correlation $(r=0.98)$ between contour distance below which contour interaction occurs and minimum angle of resolution (MAR). Because the MAR varies linearly with retinal eccentricity (Weymouth, 1958), and so does receptive field size, the authors were led to the conclusion that the basis of contour interaction might be linked to receptive field size. Because Weymouth (1958, p. 113) linked the MAR to ganglion cell density, one might think of the ganglion cell layer as a site where the interaction occurs. It should be critically noted, however, that Flom, Weymouth, and Kahneman (1963) did not explicitly look at peripheral contour interaction, and also that the reported linear relationship relied mainly on only four amblyopic eyes. Stuart and Burian (1962, Figure 2), studying "separation difficulty" in 38 amblyopic eyes, showed that there was a great variability of the crowding effect in amblyopes. Shortly thereafter, Flom, Heath, and Takahashi (1963), by studying contralateral contour interaction, presented evidence that contour interaction takes place "at a level in the visual system at which sensory information from the two eyes has already come together." They thus explicitly ruled out the ganglion cell layer. Taylor and Brown (1972) similarly ruled out the retina as a site for "lateral visual masking" (i.e., crowding). Shaw (1969) looked at the readability of shortly presented 10-letter strings subtending $4.3^{\circ}$ with a letter separation of $0.22^{\circ}$. They ruled out (among other factors) retinal sensitivity (p. 261), voluntary attention (p. 261), and masking (p. 262) as relevant factors. Their task was dissimilar from our task, however, and factors such as (involuntary) reduced focusing of attention can be expected to have had a higher influence in their task. As an aside, it might be mentioned that, as Wertheim already noticed in 1894 , dioptrics play no role in peripheral visual acuity (Millodot, Johnson, Lamont, \& Leibowitz, 1975).

A possible mechanism for explaining the crowding phenomenon is that in the periphery, when there is more than one stimulus, it is difficult for the visual system to tell the stimuli apart and to know where they are. It is clear that under some circumstances separate stimuli are not processed independently of each other. Wagner $(1918, p .70)$, for example, found that the recognizability of foveally presented words was enhanced by a previous peripheral presentation even though the peripheral presentation was not identified and did not cause a shift in attention. Geiger and Lettvin (1986) have reported the complementary finding that the identification of peripheral patterns is enhanced by simultaneous foveal presentation of the same patterns.

The process of forming the percept of a peripherally presented stimulus does not occur instantly but seems to take some time. Korte (1923) provided extensive phenom- 
enological descriptions of how this process develops, from the presentation of the physical stimulus to the stabilizing of the final percept. Korte proposed that this process was made up of two stages. In the first stage, a passive overall impression of the stimulus is formed. The second stage is an active process of multiple feature selection and competition between alternate percepts. More recent observations have confirmed that it is possible for a person to retain some aspects of patterns viewed in peripheral vision while at the same time failing to form a correct perception of the shape. Sharpness of edges is retained (Bouma, 1971; Lettvin, 1976), for example, while spatial position is degraded (Rentschler \& Treutwein, 1985; Saarinen, 1987). A similar loss of form without loss of sharpness is also reported for amblyopic vision (Brettel, Caelli, Hilz, \& Rentschler, 1982; Weiss, Rentschler, \& Caelli, 1985). The results of the present experiment lead us to conclude that peripheral pattern vision cannot be treated as a simple, degraded version of foveal vision. Taken together with the work just discussed, this makes it clear that peripheral vision must be viewed as a set of complex dynamic processes that cause stimuli to interact in nonlinear ways. It is not obvious how best to model such a system, but the current work in interconnected network models of vision (Arbib \& Hanson, 1987; Minsky, 1985) holds much promise for our understanding of the dynamic nature of peripheral vision.

Our findings lead us to advocate a more extensive use of contrast thresholds for optotype-like targets. Contrast thresholds can be reliably determined; they show a certain independence from background luminance conditions; other variables of interest, such as size and presentation time, can be varied independently; and there is the possibility of relating the findings to the large body of results obtained with gratings and more complex patterns.

\section{REFERENCES}

ANSTIS, S. M. (1974). A chart demonstrating variations in acuity with retinal position. Vision Research, 14, 589-592.

ArbiB, A., HANSON, A. R. (Eds.) (1987). Vision, brain, and cooperative computation. Cambridge, MA: MIT Press.

Atkinson, J., ANKer, S., Evans, C., \& MCInTYRe, A. (1987). The Cambridge Crowding Cards for preschool visual acuity testing. In M. Lenk-Schäfer (Ed.), Transactions of the 6th International Orthoptic Congress, Harrogate, U.K. (Reprints may be obtained from Mrs. M. Lenk-Schäfer, Hintere Ledergasse 23, D-8500 Nümberg, Germany)

Atkinson, J., Pimm-Smith, E., Evans, C., Harding, G., BradDICK, O. (1986). Visual crowding in young children. Documenta Ophthalmologica Proceedings Series, 45, 201-213.

AUBERT \& FoERSTER (1857). Beiträge zur Kenntniss des indirecten Sehens: I. Untersuchungen über den Raumsinn der Retina. Archiv für Ophthalmologie, 3, 1-37.

AulmoRn, E. (1960). Sehschärfeprïfung am Perimeter. Berichte der deutschen ophthalmologischen Gesellschaft, 63, 285-288.

AULноRN, E. (1964). Über die Beziehung zwischen Lichtsinn und Sehschärfe. Albrecht von Graefes Archiv fur Ophthalmologie, 167, 4-74.

Aulhorn, E., \& HaRms, H. (1972). Visual perimetry. In D. Jameson \& L. M. Hurvich (Eds.), Handbook of sensory physiology: Vol. 7. Part 4. Visual psychophysics (pp. 102-145). New York: Springer.
Averbach, E., Coriell, A. S. (1961). Short-term memory in vision. Bell System Technical Journal, 40, 309-328.

BoumA, M. (1970). Interaction effects in parafoveal letter recognition. Nature, 226, 177-178.

Bouma, H. (1971). Visual recognition of isolated lower-case letters. Vision Research, 11, 459-474.

Bourdon, B. (1902). La Perception visuelle de l'espace. Paris: Schleicher.

Braddick, O., Campbell, F. W., A Atrinson, J. (1978). Channels in vision: Basic aspects. In R. Held, H. W. Leibowitz, \& H. L. Teuber (Ed.), Handbook of sensory physiology: Vol. 8. Perception (pp. 3-38). New York: Springer.

Brettel, H., Caelli, T., Hilz, R., \& Rentschler, I. (1982). Modelling perceptual distortion: Amplitude and phase transmission in the human visual system. Human Neurobiology, 1, 61-67.

Broadbent, D. E. (1958). Perception and communication. London: Pergamon.

BuRBECK, C. A., Y YA, Y. L. (1990). Two mechanisms for localization? Evidence for separation-dependent and separation-independent processing of position information. Vision Research, 30, 739-750.

CaElL, T. (1986). Digital image-processing techniques for the display of images and modeling of visual perception. Behavior Research Methods, Instruments, \& Computers, 18, 493-506.

Cowey, A., Rol.Ls, E. T. (1974). Human cortical magnification factor and its relation to visual acuity. Experimental Brain Research, 21, 447-454.

DANiEL, P. M., \& Whitreridge, D. (1961). The representation of the visual field on the cerebral cortex in monkeys. Journal of Physiology, 159, 203-221.

Duncan, J. (1985). Visual search and visual attention. In M. I. Posner \& O. S. M. Marin (Eds.), Attention and performance XI (pp. 85-106). Hillsdale, NJ: Erlbaum.

EHLERS, H. (1936). The movements of the eyes during reading. Acta Ophthalmologica, 14, 56.

EHLERS, H. (1953). Clinical testing of visual acuity. A. M. A. Archives of Ophthalmology, 49, 431-434.

Eriksen, C. W., \&ofrmann, J. E. (1972). Temporal and spatial characteristics of selective encoding from visual displays. Perception \& Psychophysics, 12, 201-204.

Fendick, M., \& Westheimer, G. (1983). Effects of practice and the separation of test targets on foveal and peripheral stereoacuity. $\mathrm{Vi}$ sion Research, 23, 145-150.

FLECK, H.-J. (1987). Zur peripheren Wahrnehmung von Sehzeichen (Fortschritt-Berichte VDI). Düsseldorf: VDI-Verlag.

Flom, M. C., Heath, G., Takahaski, E. (1963). Contour interaction and visual resolution: Contralateral effect. Science, 142, 979-980.

Flom, M. C., Weymouth, F. W., \& Kahneman, D. (1963). Visual resolution and contour interaction. Journal of the Optical Society of America, 53, 1026-1032.

Geiger, G., \& LeTTVIN, J. Y. (1986). Enhancing the perception of form in peripheral vision. Perception, 15, 119-130.

HALL, J. L. (1968). Maximum-likelihood sequential procedure for estimation of psychometric functions. Journal of the Acoustical Society of America, 44, 370. (Abstract No. A-N9).

HARVEY, L. O., JR. (1986). Efficient estimation of sensory thresholds. Behavior Research Methods, Instruments, \& Computers, 18, 623-632.

Harvey, L. O., JR., Pöppel, E. (1972). Contrast sensitivity of the human retina. American Journal of Optometry, 49, 748-753.

Harvey, L. O., JR., Rentschler, I., \& Weiss, C. (1985). Sensitivity to phase distortions in central and peripheral vision. Perception \& Psychophysics, 38, 392-396.

HeRING, E. (1899). Über die Grenzen der Sehscharfe (Berichte über die Verhandlungen der Königlich-Sächsischen Gesellschaft der Wissenschaften zu Leipzig/Mathematisch-Physische Classe; Naturwissenschaftlicher Teil, 16-24).

Hilz, R., Cavonius, C. R. (1974). Functional organization of the peripheral retina: Sensitivity to periodic stimuli. Vision Research, 14, 1333-1337. 
Hilz, R., Rentschler, I., Brettel, H. (1981). Insensitivity of peripheral vision to spatial phase. Experimental Brain Research, 43, 111-114.

HÜBNER, M., RENTSCHLER, I., \& ENCKE, W. (1985). Hidden-face recognition: Comparing foveal and extrafoveal performance. Human Neurobiology, 4, 1-7.

Johnson, C. A., Keltner, J. L., \& Balestrery, F. (1978). Effects of target size and eccentricity on visual detection and resolution. $\mathrm{Vi}$ sion Research, 18, 1217-1222.

KELLY, D. H. (1984). Retinal inhomogeneity: I. Spatiotemporal contrast sensitivity. Journal of the Optical Society of America A, 1, $107-113$.

Koenderink, J. J., Bouman, M. A., Bueno de Mesquita, A. E., \& SLAPPENDEL, S. (1978). Perimetry of contrast detection thresholds of moving spatial sine wave patterns: I-IV. Journal of the Optical Society of America, 68, 845-865.

KoRTE, W. (1923). Über die Gestaltauffassung im indirekten Sehen. Zeitschrift fü Psychologie, 93, 17-82.

LetTVIN, J. Y. (1976). On seeing sidelong. The Sciences, 16, 10-20.

LEVI, D. M., \& KeIN, S. A. (1986). Sampling in spatial vision. Nature, 320, 360-362.

LeVI, D. M., Klein, S. A., \& Artsebaomo, A. P. (1985). Vernier acuity, crowding and cortical magnification. Vision Research, 25, 963-977.

LIE, I. (1980). Visual detection and resolution as a function of retinal locus. Vision Research, 20, 967-974.

LUDVIGH, E. (1941). Extrafoveal visual acuity as measured with Snellen test letters. American Journal of Ophthalmology, 24, 303-310.

Millodot, M., Johnson, C. A., LAmont, A., \& Leibowitz, H. W. (1975). Effect of dioptrics on peripheral visual acuity. Vision Research, 15, 1357-1362.

MinSKY, M. (1985). The society of mind. New York: Simon \& Schuster.

MonTI, P. M. (1973). Lateral masking of end elements by inner elements in tachistoscopic pattern perception. Perceptual \& Motor Skills, 36, $777-778$

MoRGAN, M. J., \& WATt, R. J. (1982). The modulation transfer function of a display oscilloscope: Measurements and comments. Vision Research, 22, 1083-1085.

OGLe, K. N. (1950). Binocular vision. Philadelphia: Saunders.

PARTH, P., \& RENTSCHLER, I. (1984). Numerosity judgements in peripheral vision: Limitations of the cortical magnification hypothesis. Behavioural Brain Research, 11, 241-248.

Pelli, D. G., Robson, J. G., \& Wilkins, A. J. (1988). The design of a new letter chart for measuring contrast sensitivity. Clinical Vision Sciences, 2, 187-199.

Pentland, A. (1980). Maximum likelihood estimation: The best PEST Perception \& Psychophysics, 28, 377-379.

Perry, V. H., \& Cowey, A. (1988). The lengths of the fibres of Henle in the retina of macaque monkeys: Implications for vision. Neuroscience, 25, 225-236.

PöPPEL, E., \& HARVEY, L. O. (1973). Light-difference threshold and subjective brightness in the periphery of the visual field. Psychologische Forschung, 36, 145-161.

PoINTER, J. S. (1986). The cortical magnification factor and photopic vision. Biological Reviews of the Cambridge Philosophical Society, 61, 97-119.

REGAN, D. (1988a). Low-contrast letter charts and sinewave grating tests in ophthalmological and neurological disorders. Clinical Vision Sciences, 2, 235-250.

REGAN, D. (1988b). Low-contrast visual acuity for pediatric use. Canadian Journal of Ophthalmology, 23, 224-227.

ReNTSCHLER, I., \& TReUTwern, B. (1985). Loss of spatial phase relationships in extrafoveal vision. Nature, 313, 308-310.

Rovamo, J., \& Virsu, V. (1979). An estimation and application of the human cortical magnification factor. Experimental Brain Research, 37, 495-510.
Rovamo, J., Virsu, V., \& NÄsÄnen, R. (1978). Cortical magnification factor predicts the photopic contrast sensitivity of peripheral vision. Nature, 271, 54-56

SAARINEN, J. (1987). Perception of positional relationships between line segments in eccentric vision. Perception, 16, 583-591.

SCHWARTZ, E. L. (1980). Computational anatomy and functional architecture of striate cortex: A spatial mapping approach to perceptual coding. Vision Research, 20, 645-669.

SHAw, P. (1969). Processing of tachistoscopic displays with controlled order of characters and spaces. Perception \& Psychophysics, 6 , 257-266.

Spinelli, D., Bazzeo, A. \& Vicario, G. B. (1984). Orientation sensitivity in the peripheral visual field. Perception, 13, 41-47.

StuART, J. A., \& BURIAN, H. M. (1962). A study of separation difficulty: Its relationship to visual acuity in normal and amblyopic eyes. American Journal of Ophthalmology, 53, 471.

TAYLOR, S. G., \& BROWN, D. R. (1972). Lateral visual masking: Supraretinal effects when viewing linear arrays with unlimited viewing time. Perception \& Psychophysics, 12, 97-99.

THOMAS-DECoRTS, G. (1959). Acuite visuelle angulaire et acuite visuelle morphoscopique dans l'amblyopie ex anopsia. Bulletin de la Société Belge d'Ophtalmologie, 123, 488-499.

TolhurSt, D. J., \& LiNG, L. (1988). Magnification factors and the organization of the human striate cortex. Human Neurobiology, 6 , 247-254.

ToWNSEND, J. T., TAYLoR, S. G., \& Brown, D. R. (1971). Lateral masking for letters with unlimited viewing time. Perception \& Psychophysics, 10, 375-378.

Van Essen, D. C., Newsome, W. T., \& Maunsell, H. R. (1984). The visual field representation in striate cortex of the macaque monkey: Asymmetries, anisotropies, and individual variability. Vision Research, 24, 429-448.

VIRSU, V., NÄsÄNEN, R., \& OSMOVITTA, K. (1987). Cortical magnification and peripheral vision. Journal of the Optical Society of America $A$ 4, 1568-1578.

VIRSU, V., Rovamo, J. (1979). Visual resolution, contrast sensitiv ity and the cortical magnification factor. Experimental Brain Research 37, 475-494.

Virsu, V., Rovamo, J., LAurinen, P., \& NÄsänen, R. (1982). Temporal contrast sensitivity and cortical magnification. Vision Research 22, 1211-1217.

WÄsSLE, H., GRÜNERT, U., RöHRENBECK, J., \& BOYCOTT, B. B. (1989) Cortical magnification factor and the ganglion cell density of the primate retina. Nature, 341, 643-646.

WAGNER, J. (1918). Experimentelle Beiträge zur Psychologie des Lesens Zeitschrift fur Psychologie, 80, 1-75.

Watson, A. B., \& Pell, D. G. (1983). QUEST: A Bayesian adaptive psychometric method. Perception \& Psychophysics, 33, 113-120.

WeIss, C., Rentschler, I., \& CAELL, T. (1985). Amblyopic processing of positional information: Part II. Sensitivity to phase distortion. $E x$ perimental Brain Research, 60, 279-288.

WERTHEIM, T. (1894). Über die indirekte Sehschärfe. Zeitschrift fü Psychologie und Physiologie der Sinnesorgane, 7, 172-187.

Westheimer, G. (1982). The spatial grain of the perifoveal visual field Vision Research, 22, 157-162.

WEYMOUTH, F. W. (1958). Visual sensory units and the minimal an gle of resolution. American Journal of Ophthalmology, 46, 102-113

WOLFORD, G., \& CHAMBERS, L. (1983). Lateral masking as a function of spacing. Perception \& Psychophysics, 33, 129-138.

WoODrow, H. (1938). The effect of pattern upon simultaneous letter span. American Journal of Psychology, 51, 83-96.

(Manuscript received July 9, 1990; revision accepted for publication December 31,1990 .) 